\title{
POSSÍVEIS IMPACTOS DAS POLITICAS DE AVALIAÇÃO NO CURRÍCULO ESCOLAR
}

\author{
SANDRA M. ZÁKIA L. SOUSA \\ Faculdade de Educação da Universidade de São Paulo \\ sanzakia@usp.br \\ RESUMO
}

\begin{abstract}
Iniciativas de avaliação direcionadas aos diversos níveis de ensino, que se inserem em um movimento de redefinição do papel do Estado na gestão das políticas educacionais, foram desencadeadas no Brasil, particularmente a partir da última década do século XX. Fortalecendo mecanismos discriminatórios, os delineamentos adotados tendem a provocar impactos nos currículos escolares, no sentido de sua uniformização e enrijecimento. Tendo como foco iniciativas do governo federal, como a implantação do Sistema Nacional de Avaliação da Educação Básica - Saeb -, o Exame Nacional do Ensino Médio - Enem - e o Exame Nacional de Cursos-ENC -, destacam-se, neste texto, suas principais características, observando-se, no caso dos exames, seu potencial de condicionar os currículos e, desse modo, intensificar desigualdades escolares e sociais.
\end{abstract}

AVALIAÇÃO EDUCATIVA - POLÍTICAS PÚBLICAS

\section{ABSTRACT}

POSSIBLE IMPACTS OF EVALUATION POLICIES ON THE SCHOOL CURRICULUM. Evaluation initiatives directed at different levels of teaching were undertaken in Brazil, especially since the last decade of the $20^{\text {h }}$ century, within a movement to redefine the role of the state in the management of educational policies. The outlines adopted, which fortify the mechanisms of discrimination, tend to provoke rigidity and standardization of school curricula. Focusing on initiatives by the federal government such as the implementation of the National System to Evaluate Primary Education - the Saeb -, the National High School Examination - the ENEM and the National College Examination - the ENC -, this text highlights their major features and, in the case of the examinations, notes their potential to condition the curricula, thus intensifying both educational and social inequalities.

EDUCATIONAL POLICIES - PUBLIC POLICIES

Reprodução parcial de texto elaborado para o $11^{\circ}$ Encontro Nacional de Didática e Prática de Ensino -Endipe -, integrando o simpósio Políticas educacionais, práticas escolares e objetivos de aprendizagem: repercussões na sala de aula, realizado em 29 maio 2002, acrescentando-se considerações sobre o Exame Nacional de Cursos para apresentação na 25a Reunião Anual da ANPEd, sessão especial intitulada "Políticas de avaliação e repercussões na prática pedagógica", em 2 out. 2002. 
Não se pode falar de impactos de políticas de avaliação abstratamente, sendo necessário situar que procedimento ou processo estamos tomando como referência. Eventuais influências que a avaliação possa provocar no desenvolvimento do currículo escolar devem-se a finalidades e contornos de que ela se revestir. Assim, a apreciação de seus efeitos e impactos, sejam positivos ou negativos, só é possível realizar quando se toma para análise uma iniciativa concreta.

Neste texto, focalizamos o Sistema Nacional de Avaliação da Educação Básica - SAEB -, o Exame Nacional do Ensino Médio - Enem - e o Exame Nacional de Cursos - ENC -, implementados, no Brasil, pelo poder executivo federal. Esses sistemas se apresentam como avaliações de escolas, de egressos do ensino médio e de concluintes do ensino superior, respectivamente. A partir de uma sucinta caracterização destas iniciativas, nosso propósito é indicar possíveis impactos no currículo escolar.

Falamos em possíveis impactos uma vez que tais iniciativas são recentes e não permitem apreciações de natureza conclusiva, demandando a realização de estudos empíricos'. O que é tomado como parâmetro para análise é o delineamento destas avaliações, relacionando-as ao papel que tem sido assumido pelo Estado na implementação das políticas sociais.

A partir de considerações que procuram situar as iniciativas de avaliação do âmbito educacional no processo de redefinição do papel de Estado, o texto desenvolve-se em torno de dois pontos:

- Especificidade do Saeb, do Enem e do ENC;

- Possíveis implicações destas iniciativas de avaliação em curso no país.

\section{REDEFINIÇÃO DO PAPEL DO ESTADO E AVALIAÇÃO}

A avaliação tem ocupado lugar central nas políticas educacionais em curso no país, constituindo-se em um dos elementos estruturantes de sua concretização, nos moldes em que vem sendo concebida, particularmente a partir da década de 90 .

Assume-se como uma estratégia capaz de propiciar o alcance dos objetivos de melhoria da eficiência e da qualidade da educação, os quais têm sido declarados em planos e propostas governamentais, direcionadas às várias instâncias e instituições dos sistemas de ensino.

I No caso do ENC identificamos duas pesquisas concluídas. 
Melhoria da eficiência refere-se ao fluxo escolar (taxas de conclusão, de evasão, de repetência, estimulando-se, por exemplo, a implantação da progressão continuada, classes de aceleração, organização curricular em ciclos), bem como a racionalização orçamentária (programas de avaliação de desempenho, descentralização administrativa).

Quanto à concepção de qualidade do ensino adotada, será possível sua explicitação a partir de considerações que fizermos sobre práticas de avaliação em curso, que são tomadas como principal mecanismo propulsor da qualidade e conduzidas sob pressuposto de se dar visibilidade e controle público aos produtos ou resultados educacionais, disponibilizando aos usuários elementos para escolha dos serviços ou para pressão sobre as instituiç̧ões ofertantes.

Para uma compreensão do significado atribuído à avaliação no âmbito das políticas educacionais, é necessária, mesmo que sucintamente, uma referência ao processo de redefinição do papel de Estado. Em meados dos anos 70, com a perda de dinamismo das principais economias ocidentais, o Welfare State é colocado em questão, emergindo com força a tese neoliberal de defesa do Estado-mínimo. Em oposição à intervenção estatal como suporte estrutural de viabilização das economias capitalistas, ganha espaço a defesa da não intervenção do Estado na economia, deixando que os mecanismos de mercado atuem livremente.

No Brasil, embora não tenhamos sequer tido como realidade o Estadosocial, considerando-se que a intervenção estatal delineou-se em consonância com o padrão excludente de desenvolvimento econômico, beneficiando cada vez mais segmentos menores da população, ganham espaço no debate nacional, especialmente nas políticas governamentais em realização, alternativas pautadas na perspectiva neoliberal, que apontam novos modos de organização e oferta de serviços sociais e, conseqüentemente, educacionais.

Assumindo os pressupostos que apoiam a lógica mercantilista no campo econômico e que impõem um redirecionamento do papel do Estado na economia, como condição para a eficiência e produtividade, na área educacional propostas e práticas evidenciam esse movimento, tais como as escolas cooperativas, o valeeducação, as parcerias entre Estado e empresas privadas na gestão e financiamento do ensino, a implantação de sistemas de avaliação do ensino.

Dentre as iniciativas dessa natureza, a avaliação, em nosso entender, é a que tem tido maior potencial para concretizar a transformação do papel do Estado na gestão da educação pública, o qual tem assumido como funções prioritárias a de legislar e avaliar. Comentando esse movimento, Afonso ( 1998) explora a expressão "Estado avaliador", que começa a ser utilizada a partir da década de 80 , sobretudo 
por governos neoconservadores e neoliberais de países centrais. Diz o autor que "para diferentes países, esta expressão quer significar, em sentido amplo, que o Estado adoptou um ethos competitivo, decalcado no que seria designado por neodarwinismo social, passando a admitir a lógica do mercado com a importação para o domínio público de modelos de gestão privada cuja ênfase é posta nos resultados ou produtos do sistemas educativos. Como assinala G. Walford,

...esta ideologia da privatização, ao enaltecer o capitalismo de livre-mercado, conduziu a alterações e mudanças fundamentais no papel do Estado, tanto ao nível local, como ao nível nacional. Neste sentido, por exemplo, diminuir as despesas públicas exigiu não só a adopção de uma cultura gestionária (ou gerencialista) no setor público, como também induziu a criação de mecanismos de controlo e responsabilização mais sofisticados. A avaliação aparece assim como um pré-requisito para que seja possível a implementação desses mecanismos. (apud Afonso, 1998, p. I | 3)

A referência a esse movimento de redefinição do papel do Estado, que se realiza em âmbito mundial, é importante, não para aceitá-lo como algo inexorável mas para possibilitar-nos a explicitação de princípios que têm norteado as iniciativas de avaliação educacional, no Brasil, e que, como já assinalamos, ocupam papel central nas políticas educacionais brasileiras. Se tradicionalmente o foco privilegiado era a avaliação da aprendizagem, hoje observamos propostas e práticas que, para além da avaliação do aluno, voltam-se para a avaliação do desempenho docente, avaliação de curso, avaliação institucional, avaliação do sistema educacional. Além da diversidade de focos para os quais a avaliação está direcionada, registra-se, também, que tais propostas e práticas abrangem os diversos níveis de ensino - da educação básica ao ensino superior, com especificidades para a graduação e a pósgraduação.

Manifestação de Castro (1998), dirigente integrante do MEC desde a primeira gestão do presidente Fernando Henrique Cardoso, em 1995, é ilustrativa do lugar estratégico da avaliação na gestão educacional. Constatando a remodelação do papel do Estado, a autora refere-se a medidas semelhantes que vêm sendo adotadas

...em todos os países, como a privatização das empresas estatais, a desregulamentação da economia, tendo por escopo estimular os investimentos privados, a realização de parcerias com o setor empresarial para ampliação da oferta de serviços públicos e o fortalecimento do papel regulador do Estado. (p.9)

Afirma que "sai de cena o Estado-executor, assumindo seu lugar o Estadoregulador e o Estado-avaliador". 
Essa concepção do papel do Estado se concretiza no âmbito das políticas educacionais por meio das características com as quais se revestem os procedimentos de avaliação adotados pelo poder executivo federal, que têm sido referência para todo o território nacional e reproduzem em propostas de governos estaduais e municipais, imprimindo assim uma lógica dominante de gestão educacional.

\section{CONSIDERAÇÕES SOBRE O SAEB}

No Brasil, registra-se desde a década de 60 a ampliação do uso de testes educacionais (Gatti, 1987); no entanto, situa-se nos anos finais da década de 80 a primeira iniciativa de organização de uma sistemática de avaliação do ensino fundamental e médio, em âmbito nacional. Esta sistemática, é denominada pelo MEC, a partir de 1991, Sistema Nacional de Avaliação da Educação Básica². Este toma como um dos indicadores da avaliação o desempenho em provas de uma amostra de alunos do ensino fundamental e médio, de todas as unidades federadas.

Conforme Relatório nacional do Sistema de Avaliação do Ensino Básico de 1990 (Brasil, I99I), pretende-se, com o estudo de rendimento dos alunos,

... detectar, primeiramente, os problemas de ensino-aprendizagem existentes e, em segundo lugar, determinar em que condições (de gestão, de competência docente, de alternativas curriculares, etc.) são obtidos melhores resultados e que áreas exigem uma intervenção para melhorar as condições de ensino. (p.7)

Para tanto, além de medir o desempenho escolar, o Saeb coleta informações sobre características dos alunos, professores e diretores, bem como das condições físicas e equipamentos das escolas.

Define-se o Saeb como um sistema de monitoramento contínuo, capaz de subsidiar as políticas educacionais, tendo como finalidade reverter o quadro de baixa qualidade e produtividade do ensino, caracterizado, essencialmente, pelos índices de repetência e evasão escolar.

O delineamento assumido pelo Saeb encontra respaldo em argumentos que justificam a avaliação como instrumento de gestão educacional, tais como: possibilidade de compreender e intervir na realidade educacional, necessidade de controle de resultados pelo Estado, estabelecimento de parâmetros para comparação e clas-

2 Caracterização mais detalhada das alterações ocorridas no Saeb, desde a primeira iniciativa em 1988, é apresentada por Bonamino (2002). 
sificação das escolas, estímulo à escola e ao aluno por meio da premiação, possibilidade de controle público do desempenho do sistema escolar ${ }^{3}$.

Esses argumentos expressam, no limite, uma concepção do papel do Estado na condução das políticas educacionais. Ao que parece, a questão central nesta proposta não é a de buscar subsídios para intervenções mais precisas e consistentes do poder público, ou seja, uma análise das informações coletadas para definição e implementação de políticas para a educação básica, mas difundir nos sistemas escolares uma dada concepção de avaliação, que tem como finalidade a instalação de mecanismos que estimulem a competição entre as escolas, responsabilizando-as, em última instância, pelo sucesso ou fracasso escolar.

Mesmo considerando que o Saeb, por seu desenho amostral, não permite comparação entre a totalidade das escolas de cada unidade federada, observa-se que estabelece a comparação e classificação das unidades federadas, estimulando a competição entre elas com o objetivo de galgarem melhores postos no ranking das unidades escolares. A título de exemplo, lembramos de uma unidade federada que assumiu como alvo a ser atingido "entrar no G7", o que significava ser classificada, a partir dos resultados do Saeb, entre as sete "melhores" do país.

Ao comentar sobre eventuais impactos do Saeb, Bonamino considera que,

...na sua forma atual, o Saeb não parece possuir o poder de influenciar o estilo cognitivo dos alunos e professores em cada disciplina escolar. O Saeb ainda não pode ser considerado como uma avaliação reguladora da aprendizagem, nem como uma avaliação formativa, baseada na constante explicitação dos elementos a considerar, das estratégias a adotar, dos problemas a resolver. [...] Para equacionar mais adequadamente o alcance e o impacto que o Saeb pode vir a ter sobre os aspectos mencionados, certamente será necessário acompanhar a forma como os estados estão entendendo e implementando a denominada cultura de avaliação. É sempre possível, e já há alguns sinais concretos a respeito, que ao reverberar nos estados e municípios o modelo sofra uma reconversão, passando a tornar-se censitário. Nesses casos, ele se tornaria mais propenso a aderir "as teses sobre a regulação pedagógica e financeira da vida escolar que, até o momento o desenho do Saeb parece não endossar". (2002, p. 181-182)

Aceita a suposição de que o Saeb, pelo seu delineamento, não tem potencial para produzir alterações nas práticas escolares, de ensino e de aprendizagem, no

3 A título de ilustração de como são apresentados tais argumentos ver Waiselfisz, 1993; Castro, 1994; Instituto Herbert Levy, 1993; Fletcher, 1994. 
sentido de seu aprimoramento, cabe uma indagação: qual a sua intencionalidade? Sua finalidade parece ser o fortalecimento do papel regulador do Estado, por meio da responsabilização das unidades federadas pelos resultados escolares. Como disse Castro, em conferência intitulada "Projeto nacional: o papel da avaliação da educação", " ...a tendência vai no sentido de descentralizar o que for possível. A idéia geral é: o Governo Federal não tem que fazer, ele faz acontecer" (Castro, 1996, p. 14). E, um meio de "fazer acontecer" é estimular a competição.

Se com o Saeb o que se provoca é a competição entre unidades federadas, no caso de sistemas criados pelas próprias unidades federadas, com desenho censitário, esta lógica competitiva é transferida para as escolas, acrescida do poder de conformar os currículos escolares. Nessa perspectiva, vale lembrar o significado que podem assumir os Parâmetros Curriculares Nacionais, quanto à constituição de padrões de desempenho esperados, ou seja, os conteúdos a serem ensinados nas escolas serão os "cobrados" nas provas elaboradas pelas instâncias externas à escola.

Para evidenciar a possibilidade de uso de resultados de sistemas de avaliação para premiação ou punição de escolas, o que certamente potencializa o poder dos testes de rendimento virem a conformar o que se ensina nas escolas, reproduzimos uma notícia divulgada em janeiro de 2002, a respeito do estado de São Paulo, cujo sistema de avaliação é censitário. $\bigcirc$ título é "Governo paulista premia escolas e alunos com maior desempenho", seguido do seguinte texto:

I0; 01 - Das 345 escolas selecionadas de um total de 4. 100 estabelecimentos, 25 receberam pacotes de viagens para a região amazônica. Os demais roteiros das viagens realizadas em dezembro último incluíram Brasília e região do Distrito Federal, Salvador e Porto Seguro e cidades históricas de Minas Gerais, Rio de Janeiro e Petrópolis (sic), Paraná e Santa Catarina. Mais 7 mil pessoas de 782 escolas estarão viajando até março próximo para municípios do interior paulista. Neste programa estão sendo investidos cerca de R\$ 4 milhões. (Disponível em: <http://ultimosegundo. ig.com.br>. Acesso em: janeiro de 2002)

Não se pretende, com as considerações esboçadas, desprezar o valor da avaliação externa, na qual se situa a apreciação do trabalho escolar pelas instâncias administrativas do sistema e que, no entanto, não deve ser traduzida na aplicação de testes de rendimento escolar. Potencializar a dimensão educativa/formativa da avaliação, supõe, certamente, a promoção da autonomia pedagógica e didática da escola e não a sua conformação, que ocorre ao se delimitar o conhecimento que deve ser legitimado pela escola, cujo cumprimento é condição para sua premiação. 


\section{CONSIDERAÇÕES SOBRE O ENEM}

Exame Nacional do Ensino Médio tem uma especificidade a ser observada: apresenta-se como um exame em que o aluno é que decide sobre a conveniência de participar, após conclusão do ensino médio, sob a promessa de que "seu futuro passa por aqui", frase utilizada em um material informativo do exame, divulgado pelo Instituto Nacional de Estudos Pedagógicos - Inep.

De modo explícito, fica demonstrada a visão individualizada com que é tratado o processo educacional, sendo atribuída, ao aluno, individualmente, a responsabilidade pelas eventuais competências ou incompetências evidenciadas pelo exame. No documento do Inep, já mencionado, lê-se: "O Enem poderá lhe mostrar, enfim, em que áreas você precisa caprichar ainda mais para ter sucesso pessoal e profissional. Desse modo, você terá uma avaliação do seu potencial e poderá tomar as decisões mais adequadas aos seus desejos e às suas escolhas futuras". Em nenhum momento se lê algo como: o Enem poderá mostrar, enfim, quais vêm sendo os resultados das ações empreendidas pelos órgãos governamentais. $\mathrm{Ou}$ algo do tipo: MEC: seu futuro passa por aqui!

Além de atribuir ao potencial do aluno o seu sucesso pessoal e profissional, abstraindo os fatores econômicos e sociais que lhe condicionam tal ou qual trajetória escolar e social, cabe ainda observarmos que, tal como se apresenta, o Enem, tende, no limite, a prejudicar os alunos oriundos de escolas que contam com precárias condições de funcionamento, oferecidas pelo poder público, que, tradicionalmente, atendem à população pobre.

Trata-se, portanto, de uma medida de resultado final, interpretada em uma perspectiva individualizada, desconsiderando as condições do sistema de ensino que, sem dúvida, induzem a produção de "competências" ou "incompetências" nos alunos.

Cabe ainda indagarmos que benefícios poderá trazer aos alunos e o que poderá ser feito retroativamente? Diante da constatação de dadas incompetências, o que poderá um aluno egresso da escola pública fazer? Exigir do poder público um processo de ensino que garanta seu direito à real escolarização? Nada nessa direção é expresso nos seus objetivos, elencados no "Documento Básico", elaborado pelo Inep/MEC.

Ao que parece, pelos objetivos anunciados, o Enem pretende legitimar-se como mecanismo de referência a processos seletivos, seja para cursos profissionalizantes, para cursos superiores ou mesmo para inserção no mercado de trabalho. 
Será que é neste sentido que devem ser conduzidos os esforços e recursos de um Ministério da Educação? Em um país com altos índices de exclusão educacional e social, que sentido têm iniciativas voltadas para classificação de alunos, de acordo com competências individuais, medidas por meio de testes?

Buscar responder essas questões, que possibilitam dar transparência às políticas em curso, deve ser um passo que antecede a decisão de "adotar os resultados do Enem", seja qual for o processo seletivo em pauta, pois sua adoção significa, no limite, a legitimação não apenas do Enem mas das diretrizes e dos propósitos da política vigente.

Comparando-se com o Saeb, é possível afirmar que o Enem apresenta-se com um potencial maior de condicionar os currículos escolares, ou seja, ensina-se para se obter bons resultados no exame. Aliás já existem até "cursinhos" preparatórios para o Enem!

\section{CONSIDERAÇÕES SOBRE O ENC}

Com relação à avaliação do ensino superior, particularmente sobre a graduação, contamos com estudos que têm registrado e analisado sua evolução no Brasil, trazendo importantes informações e reflexões, que possibilitam compreender os programas governamentais implementados nos anos recentes. Tais estudos têm tido como espaço privilegiado para sua divulgação a Revista da Rede de Avaliação Institucional da Educação Superior ${ }^{4}$, alguns dos quais tomo como referência para sumariar as propostas e práticas em curso.

Atualmente, embora não tenha sido formalmente extinto o Programa de Avaliação Institucional das Universidades Brasileiras - Paiub -, que vinha sendo conduzido pela Secretaria da Educação Superior do MEC, desde 1994, com adesão das universidades, o que têm ganho visibilidade como procedimento de avaliação das instituições de ensino superior, são os exames nacionais, instituídos em lei ${ }^{5}$, destinados a "aferir os conhecimentos e competências adquiridos pelos alunos em fase de conclusão dos cursos de graduação". Este foi o único procedimento de avaliação citado no texto da referida lei, embora faça referência a que o MEC fará uso "de procedimentos e critérios abrangentes dos diversos fatores que determinam a qualidade e a eficiência das atividades de ensino, pesquisa e extensão".

4 A revista é uma publicação da Rede de Avaliação Institucional da Educação Superior - Raies.

5 Lei n. 9.131, de 24 nov. 85, art. 3, que altera dispositivos da Lei n. 4.024/61, trata da criação do Conselho Nacional de Educação e institui os "Exames Nacionais". 
Ou seja, de uma perspectiva de avaliação institucional, abrangente e processual, que tem sido construída por meio do Paiub ${ }^{6}$, para se dar ênfase aos resultados obtidos individualmente pelos alunos, em provas realizadas ao final de um curso. Embora não formalmente, tal encaminhamento foi expressão da "desativação" do Paiub. O destaque dado para a avaliação de produto não promove a consolidação de uma cultura de avaliação no interior das instituições, que vinha sendo estimulada pelo Paiub. Ao contrário, tende a reduzir a atividade avaliativa ao procedimento de medida ou quantificação de resultados, sendo monopólio do governo federal a determinação de que produtos são considerados valiosos. Ou seja, estamos assistindo ao uso da avaliação como dispositivo de regulação educacional e social.

○ "provão", como é chamado o Exame Nacional de Cursos, provocou críticas de alunos e de instituições universitárias. A apreciação de Belloni, a seguir, ilustra o conteúdo principal das críticas proferidas:

Trata-se de uma simples medição de resultado final, um procedimento tradicional e insuficiente de avaliação, pois não considera fatores do processo de aprendizagem e das condições institucionais. Não oferece elementos para a melhoria da instituição e do sistema pois não identifica as causas das dificuldades; não beneficia o estudante pois nada poderá ser feito retroativamente. Não corresponde, portanto, ao objetivo fundamental da avaliação qual seja o de melhoria e aperfeiçoamento das instituições ou do sistema. Além disso, pode vir a estimular o aparecimento de um comércio de cursinhos preparatórios, pois o desempenho da prova poderá se transformar em critério de diferenciação entre portadores de um mesmo diploma. (1996, p. I I)

Se as críticas feitas nessa direção não tiveram força para suspender tal procedimento de medida, possivelmente, provocaram a promulgação, pelo MEC, do Decreto n. 2.026, de 14 outubro 1996, antes mesmo que se realizasse o primeiro exame ${ }^{7}$ em novembro de 1996. O referido decreto prevê que a avaliação de cursos e de instituições de ensino superior contemple, as seguintes dimensões:

6 Para uma visão geral das características do Paiub, ver publicação na revista Avaliação (Programa..., 1996).

7 Em 1996 foram examinados os alunos concluintes dos cursos de direito, administração e engenharia civil; em 1997 foram também examinados os concluintes dos cursos de engenharia química, veterinária e odontologia. A cada ano, novos cursos vêm sendo incorporados. 
- análise dos principais indicadores de desempenho global do sistema nacional de ensino superior, por região e unidade da federação, segundo as áreas do conhecimento e o tipo ou a natureza das instituições de ensino;

- avaliação do desempenho individual das instituições de ensino, compreendendo todas as modalidades de ensino, pesquisa e extensão;

- avaliação do ensino de graduação, por curso, por meio da análise das condições de oferta pelas diferentes instituiç̧ões de ensino e pela análise dos resultados do Exame Nacional de Cursos;

- avaliação dos programas de mestrado e doutorado, por área do conhecimento.

A noção de medida de resultado é ampliada para uma perspectiva de avaliação, sendo previstos, além dos exames, a avaliação das instituiç̧̃̃es e de cursos por comissões externas e a auto-avaliação da instituição. Ou seja, a avaliação do ensino superior resultará da agregação de resultados produzidos por diferentes instâncias: pela Coordenação de Aperfeiçoamento do Pessoal de Nível Superior - Capes (pósgraduação stricto sensu); pela Secretaria de Avaliação e Informação Educacional do MEC/Sediae (exame nacional e análise de indicadores de desempenho global); por especialistas (graduação) e instituições de ensino (auto-avaliação). Como observa Cunha (1997, p.4I), "a avaliação do ensino superior no Brasil foi concebida para se desenvolver de modo fragmentado, dificilmente consolidável e compatibilizável pela Sesu", ou mesmo pelo Conselho Nacional de Educação, a quem caberá emitir parecer sobre os resultados da avaliação.

Mesmo se considerarmos que, apesar da fragmentação, a intenção é a de proceder a uma avaliação mais abrangente das instituições, ficam indagações quanto ao uso de seus resultados, especialmente quando se observa a visibilidade que têm tido na mídia as pontuações decorrentes do "provão" e o seu uso como referência de qualidade de um dado curso e, por decorrência, da instituição.

Afora o incentivo à competitividade, provocado pelo estabelecimento de ranking de instituições, que expressa a transposição da lógica de mercado para a gestão do sistema educacional, cabe indagarmos sobre possíveis usos dos resultados, seja no estabelecimento de critérios para alocação de recursos financeiros entre as instituições, tendo em conta seu bom ou mau desempenho, seja na política de financiamento do ensino superior. Temos assistido investidas com o propósito de questionar a validade de manutenção de universidades públicas gratuitas, a partir de apreciações acerca de seu custo e produtividade. 
No que se refere ao seu impacto em instituições/cursos avaliados, já é possível identificar iniciativas decorrentes do conceito obtido. Tomando como referência duas pesquisas realizadas sobre o "provão" (Santoro, 1999; Santos, 200 I), manifestações que têm sido divulgadas, sistematicamente, na imprensa, bem como depoimentos informais de profissionais vinculados a instituições de ensino superior e constatam sua influência.

A primeira delas é a aprovação de sua realização, reconhecendo que os resultados espelham aprendizagem dos alunos e esta reflete a qualidade da instituição. Santos, ao analisar o que significa esta aprovação do exame, indica que ela legitima:

a. a idéia da possibilidade de todos os alunos aprenderem da mesma forma uma lição, por estarem sujeitos à mesma percepção-impressiva;

b. a idéia de que essa aprendizagem, reificada, pode ser objetivamente medida através de uma prova;

c. que a média das notas numéricas decorrentes das provas dos alunos de uma instituição, mede também o ensino, já que estão numa relação de causa-efeito;

d. essa mesma média indica a qualidade de uma instituição e, portanto, é procedimento correto classificá-la em ordem decrescente segundo essas médias. (200 I, p. I 40)

Evidencia-se também um reconhecimento de que o ENC tem provocado uma reação das instituições, especialmente as privadas, a partir dos resultados obtidos nos exames. Embora não se possa generalizar, reproduzo o que comenta Santos na conclusão de seu estudo, a qual corrobora a maior parte das manifestações, a que temos tido acesso, de professores atuantes em instituições de ensino superior:

O ENC realmente provocou agitação nos meios acadêmicos mas, se observarmos as respostas dos professores, vemos que as ações ensejadas o foram, não no sentido da melhoria do curso, mas, no sentido de "preparar o graduando para o provão". Mudanças foram realizadas, medidas emergenciais foram tomadas, não para atualizar currículos, programas, bibliografia, inovar nos métodos didáticos, mas apenas para preparar melhor o aluno para o provão. Isso, certamente, não é melhorar a qualidade dos cursos. O fim das ações foi melhorar a nota da instituição no provão, com vistas a uma melhor classificação numa lista pública que pode levar à execração [...] os professores estão fazendo ajustamentos em seus programas de trabalho e isso, fatalmente, conduzirá à fixação de um "conhecimento oficial" [...] em âmbito nacional. (200 I, p. I4 I- I42) 
Mesmo um dos defensores públicos do provão reconhece que este tem "efeitos colaterais":

Um deles é enrijecer os currículos, tirando dos cursos a liberdade de experimentar. Outro é a questão do valor adicionado. Sabemos que $80 \%$ dos resultados são determinados por diferenças dos alunos, já no vestibular. Portanto, não podemos execrar um curso que ofereça um ensino correto cujo único pecado é ter alunos mais fracos. (Castro, 2002, p.20)

Veja-se a gravidade dos "efeitos" mencionados, que, entendo, não são colaterais, mas sim intrínsecos ao "provão": uniformizar currículos e intensificar desigualdades, em prejuízo dos já prejudicados!

Sabemos que a avaliação não é um processo meramente técnico, portanto a análise dos pressupostos e de suas conseqüências sociopolíticas é necessária. Nesse sentido

...tal como vem se buscando a transparência dos resultados do trabalho universitário, há que se exigir igual tratamento aos órgãos governamentais que, de fato, detêm, atualmente, o poder de mando da educação [...] seria a avaliação das reais perspectivas governamentais, da visão que esses organismos detêm sobre a Universidade. (Amorim, Sousa, 1994, p. I27)

\section{POSSÍVEIS IMPLICAÇÕES DAS INICIATIVAS DE AVALIAÇÃO}

É possível apreender algumas características que estão presentes nos procedimentos adotados pelo poder executivo federal, quais sejam:

- ênfase nos produtos ou resultados;

- atribuição de mérito tomando-se individualmente instituições ou alunos;

- dados de desempenho escalonados, resultando em classificação;

- uso de dados predominantemente quantitativos;

- destaque à avaliação externa, não articulada à auto-avaliação.

A avaliação, pautada por tais características, tende a imprimir uma lógica e dinâmica organizacional nos sistemas de ensino, que se expressam no estímulo à competição entre as instituições educacionais e no interior delas, refletindo-se na forma de gestão e no currículo. Quanto ao currículo, destaca-se sua possível conformação aos testes de rendimento aplicados aos alunos, que tendem a ser vistos como os delimitadores do conhecimento que "tem valor", entendido o conheci- 
mento como o conjunto de informações a serem assimiladas pelos alunos e passíveis de testagem. Quanto à gestão, a perspectiva é o fortalecimento dos mecanismos discriminatórios.

O princípio é o de que a avaliação gera competição e a competição gera qualidade. Nesta perspectiva assume o Estado a função de estimular a produção dessa qualidade. As políticas educacionais ao contemplarem em sua formulação e realização a comparação, a classificação e a seleção incorporam, conseqüentemente, como inerente aos seus resultados a exclusão, o que é incompatível com o direito de todos à educação.

A própria luta da população por fazer valer este direito tende a se fragilizar, prevalecendo a busca por conquistas individuais. É ilustrativo desse movimento o comentário feito por Whitty (1998), sobre as reações à reforma educacional na Inglaterra e no País de Gales: "... as escolas, professores e pais enfrentam-se como concorrentes no mercado, e resta-lhes pouco espaço em que possam explorar interesses comuns e empreender ações coletivas".

A noção de educação como direito é reduzida à condição de mercadoria, administrada com uma lógica produtivista e sob o pressuposto de padrões diferenciados de qualidade de ensino.

Se o compromisso assumido é com a democratização do ensino, há que investir na construção de propostas de avaliação que se pautem por outros princípios, tendo como finalidade subsidiar as instituições educacionais na definição de prioridades e encaminhamento de decisões que possibilitem o seu aprimoramento, com vistas ao desenvolvimento de todos os alunos. Também, os resultados da avaliação devem ser analisados como indicadores para análise do papel e da função desempenhados pelas instâncias governamentais, na construção de uma educação de qualidade para toda a população.

\section{REFERÊNCIAS BIBLIOGRÁFICAS}

AFONSO, A. J. Politicas educativas e avaliação educacional. para uma análise sociológica da reforma educativa em Portugal (1985-1995). Minho: Centro de Estudos em Educação e Psicologia, Universidade do Minho, 1998.

AMORIM, A.; SOUSA, S. M. Z. L. Avaliação institucional da universidade brasileira: questões polarizadoras. Estudos em Avaliação Educacional. São Paulo, n. I0, p. I23- 136, jul./dez. 1994.

BELLONI, I. A universidade e o compromisso da avaliação institucional na reconstrução do espaço social. Avaliação. Campinas, v. I, n. 2, p.5-I4, 1996. 
BONAMINO, A. C. de. Tempos de avaliação educacionat: o Saeb, seus agentes, referências e tendências. Rio de Janeiro: Quartet, 2002.

BRASIL. Leis, Decretos. Lei de Diretrizes e Bases da Educação Nacional: Lei n. 9.394 de 20 de dezembro de 1996. Brasília, 1996.

Lei n. 9.131 de 24 de novembro de 1995. Brasília, 1995. Altera dispositivos da Lei n. 4.024, de 20 de dezembro de 1961, e dá outras providências. Lex, v. 59, n. 2, p.2042-2045, out./dez. 1995.

BRASIL. Ministério da Educação e Cultura. Enem: documento básico. Brasília: Inep, 1999. . Enem: seu futuro passa por aqui. Brasília: Inep, 1999. Relatório nacional do Sistema de Avaliação do Ensino Básico de 1990.

Brasília, |99|.

CASTRO, C. de M. Educação brasileira: consertos e remendos. Rio de Janeiro: Rocco, 1994. Quem tem medo da avaliação? Veja, p.20, 10 jul. 2002.

CASTRO, M. H. G. Projeto nacional: o papel da avaliação da educação. In: SEMINÁRIO INTERNACIONAL DE AVALIAÇÃO DA EDUCAÇÃO, 16 a 18 de outubro de 1995. Anais.... Rio de Janeiro: Fundação Cesgranrio, 1996. p. II - 16.

O Brasil atravessa... In: SEMINÁRIO INTERNACIONAL DE AVALIAÇÃO EDUCACIONAL, I a 3 de dezembro de 1997. Anais... Brasília: MEC, Inep, Unesco, 1998. p.9-। I. (Palestra inaugural)

CUNHA, L. A. Nova reforma do ensino superior: a lógica reconstruída. Cadernos de Pesquisa. São Paulo, n. I0 I, p.20-40, jul. 1997.

FLETCHER, P. R. A Teoria de resposta ao item: medidas invariantes do desempenho escolar. Ensaio. Rio de Janeiro, v. I, n. 2, p.21-8, 1994.

GATTI, B. A. Testes e avaliações do ensino no Brasil. Educação e Seleção, n. I6, p.33-42, 1987.

GENTILI, P. Adeus à escola pública. In: GENTILI, P. (org.) Pedagogia da exclusão: o neoliberalismo e a crise da escola pública. Petrópolis: Vozes, 1995.

INSTITUTO HERBERT LEVY. Ensino fundamental e competitividade empresariat: uma proposta para a ação do governo. Rio de Janeiro: $I H L, 1993$.

PESTANA, M. I. O Sistema de avaliação brasileiro. Revista Brasileira de Estudos Pedagógicos, v. 79, n. 191 , p.65-73, jan./abr. 1998.

PILATI, O. Sistema Nacional de Avaliação da Educação Básica. Ensaio, v. 2, n. I , p. I I-30, 1994. 
PROGRAMA DE AVALIAÇÃO INSTITUCIONAL DAS UNIVERSIDADES BRASILEIRAS Paiub. Avaliação, Campinas, v. I, n. I , p.43-66, jul. 1996.

SANTORO, E. D. Exame nacional de cursos (Provão) na ótica dos alunos de Direito de uma universidade particular. 1999. Dissertação (Mestrado) Universidade Mackenzie, São Paulo.

SANTOS, W. dos. O Provão: para além do discurso oficial. Representação do professor e anatomia do modelo. 200 I. Tese (Doutorado) Pontifícia Universidade Católica de São Paulo, São Paulo.

SOUSA, S. M. Z. L. Avaliação do rendimento escolar como instrumento de gestão educacional. In: OLIVEIRA, D. A. (org.) Gestão democrática da educação. Petrópolis: Vozes, 1997.

Avaliação e políticas educacionais: iniciativas em curso no Brasil. In: HIDALGO, A. M.; SILVA, I. L. F. (org.) Educação e Estado: as mudanças nos sistemas de ensino do Brasil e do Paraná na década de 90. Londrina: UEL, 200 I p.69-100.

Avaliar para mudar. In: SEMINÁRIO ENSINO SUPERIOR EM SAÚDE: UM OLHAR PARA O FUTURO. Anais... Rio de Janeiro: Nupes/UFRJ, 1995.

WAISELFISZ, J. Sistema de avaliação do desempenho escolar e políticas públicas. Ensaio, v. I, n. I, p.5-22, 1993.

WHITTY, G. Controle do currículo e quase-mercados: a recente reforma educacional na Inglaterra e no País de Gales. In: WARDE, M. J. (org.). Novas politicas educacionais. críticas e perspectivas. São Paulo: PUC/Programa de Estudos Pós-Graduados em Educação: História e Filosofia da Educação, 1998. p. 193-213.

Recebido em: março 2003

Aprovado para publicação em: março 2003 